\title{
The role of comorbidity as a risk factor: Suicidality among patients with depressive disorders
}

\author{
Lence Miloseva, ${ }^{1}$, Vladimir Milosev 1,2 \\ ${ }^{1}$ Faculty of Medical Sciences- Goce Delcev University-Stip, North Macedonia \\ ${ }^{2}$ Clinical Hospital Stip, North Macedonia
}

Objectives: The research was guided by two major research issues. The first aim is assessment of the role of comorbidity as a risk factor in prediction of suicidality among patients with depressive disorders correlated to suicidality in patients who are suffering from depression and other mental disorders and/or somatic.The second aim is to discuss implications for prevention.

Background: Suicidal behavior is present in all forms of depressive disorders, not only in the most severe forms, although the risk of suicide increases with disease severity (Ferro, 2016). The connection of physical illness and suicidal behavior is very complex.

Materials and Methods: In the frame of the UGD supported project, the data were collected from Clinical Hospital, Stip, North Macedonia, during the period January 2015 to January 2018. The sample consists of 180 patients, aged 19-72 years. The respondents were divided on the basis of mono \& comorbid diagnosis into four subgroups: I) those with depressive disorder; II) those with depressive disorder and physical illness; III) those with depressive disorder and another mental disorder; IV) those with depressive disorder, physical illness and mental disorder, together. Data were collected using questionnaires about sociodemographic data, structure interview, medical documentation, while suicidal behavior was studied using a scale C-SSRS (Posner at all., 2011). Written informed consent was obtained by all study participants.

Results and conclusions: Specific focus was on examining the relationship of suicidal thoughts with gender and comorbidity, frequency and intensity, as well as differences in preparations, trials, ways and number of suicides. Additionally, we examined the characteristics of suicide attempt on 56 respondents and whether there was a difference among groups in terms of suicidal behavior. The results are in line with our expectations and they showed that comorbidity is a significant factor in predicting suicidal behavior (WHO, 2007; Ferro, 2016).
$>$ There is a statistically significant difference between groups with female respondents, regarding suicide attempts. The most frequent group with the number of suicide attempt is the IV group, those with depressive disorder, physical illness and mental disorder, together.

$>$ Female respondents significantly differ from male respondents regarding interrupted suicide attempt $17 \%$ of them were being stopped by someone or something else $(F=0.052, p<0.05)$.

$>$ Regarding acts or preparation towards imminently making a suicide attempt, there is no significant differences between groups.

$>$ Using of pills is the most frequent way of suicide attempt among female respondents through all participants in the sample $\mathrm{X}^{2}=14.122 ; \mathrm{df}=5 ; \mathrm{p}=0.059$.

$>$ The most frequent active and passive suicidal ideation were find in the IV group, those with depressive disorder, physical illness and mental disorder, together. However, we have not find significant differences between groups.

\begin{tabular}{|r|c|c|c|c|c|c|c|}
\hline & & $\begin{array}{c}\text { I } \\
\text { group } \\
\mathrm{N}=24\end{array}$ & $\begin{array}{c}\text { II } \\
\text { group } \\
\mathrm{N}=44\end{array}$ & $\begin{array}{c}\text { III } \\
\text { group } \\
\mathrm{N}=31\end{array}$ & $\begin{array}{c}\text { IV } \\
\text { group } \\
\mathrm{N}=81\end{array}$ & $\begin{array}{c}\mathrm{N} \\
180\end{array}$ & $\begin{array}{c}\text { Fisher } \\
\text { test } \\
p\end{array}$ \\
\hline $\begin{array}{r}\text { SUICID } \\
\text { attempt }\end{array}$ & & & & & & & \\
\hline Male & Yes & 1 & 2 & 4 & 9 & 16 & \\
& & $14.29 \%$ & $9.09 \%$ & $30.77 \%$ & $31.03 \%$ & $22.54 \%$ & \\
& No & 6 & 20 & 9 & 20 & 55 & .351 \\
& & $85.71 \%$ & $90.91 \%$ & $69.23 \%$ & $68.97 \%$ & $77.46 \%$ & \\
\hline Female & Yes & 5 & 4 & 10 & 21 & 40 & \\
& & $29.41 \%$ & $18.18 \%$ & $55.55 \%$ & $40.38 \%$ & $36.70 \%$ & \\
& No & 12 & 18 & 8 & 31 & 69 & .039 * \\
& & $70.59 \%$ & $81.82 \%$ & $44.45 \%$ & $59.62 \%$ & $63.30 \%$ & \\
\hline
\end{tabular}

I) those with depressive disorder; II) those with depressive disorder and physical illness; III) those with depressive disorder and another mental disorder; IV) those with depressive disorder, physical illness and mental disorder, together. ${ }^{*} p<0.05$

Table 1: Distribution of respondents regarding suicide attempt and comorbidity groups 